\title{
Effect of heat treatment and thermomechanical processing on microstructure and tensile property of Ti-44Al-8Nb-0.2W-0.2B-0.5Y alloy
}

\author{
*Xiao-peng Wang', Fan-tao Kong ${ }^{2}$, Xiao-ping Cao ${ }^{3}$, Shu-zhi Zhang ${ }^{3}$, Chang-jiang Zhang ${ }^{3}$, Yu-yong Chen ${ }^{2}$ \\ 1. Center of Analysis and Measurement, Harbin Institute of Technology, Harbin 150001, China \\ 2. National Key Laboratory for Precision Hot Processing of Metals, Harbin Institute of Technology, Harbin 150001, China \\ 3. School of Materials Science and Engineering, Taiyuan University of Technology, Taiyuan 030024, China
}

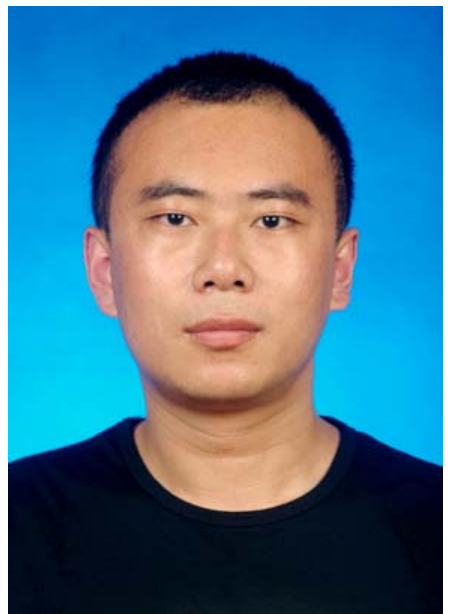

*Xiao-peng Wang

Lecture, master's superviser. His main research interests mainly focus on composition design and mechanical properties of high entropy intermetallics (HEls), precision hot-deformation of Tibased alloys and TiAl intermetallic. To date, he has published more than 30 papers, chaired or participated in more than 10 scientific research projects, including the National Natural Science Foundation projects, and National Key Research and Development Program.

E-mail: wangxiaopeng@hit.edu.cn

Received: 2020-07-30

Accepted: 2020-10-12
Abstract: High Nb-TiAl (Ti-44Al-8Nb-0.2W-0.2B-0.5Y, at.\%) ingot was fabricated by vacuum arc remelting (VAR). The as-cast ingot was hot-isostatic pressed (HIP) and homogenizing annealing processed. The influence of heat treatment temperature and thermomechanical processing on the microstructure and tensile property of the alloy was investigated by X-ray diffractometry (XRD), scanning electron microscopy (SEM) and tensile tests. It was found that the high $\mathrm{Nb}$-TiAl alloy after HIP and annealing was mainly composed of coarse $\alpha_{2} / \gamma$ lamellae, $\beta / B 2$ phase and $\gamma$ phase and the solidification path of this alloy was: $L \rightarrow L+\beta \rightarrow \beta \rightarrow \alpha+\beta \rightarrow \alpha \rightarrow \alpha+\beta+\gamma \rightarrow \alpha_{2}+\beta+\gamma$. The water quenching results showed that the alloy was in $\alpha$ single phase region at $1,340{ }^{\circ} \mathrm{C}$. After heating at $1,340{ }^{\circ} \mathrm{C}$ for $30 \mathrm{~min}$ followed by furnace cooling, the alloy showed a full lamellar microstructure and its ultimate tensile strength was about $538 \mathrm{MPa}$, with an elongation of $0.3 \%$ at room temperature. Free-crack forged pancakes with fine-grained fully lamellar structure (FFLS) were obtained with an initial deformation temperature of $1,340{ }^{\circ} \mathrm{C}$ and the ultimate tensile strength of forged alloy was about $820 \mathrm{MPa}$, with an elongation of $0.9 \%$ at room temperature, which was much higher than that of alloy after HIP and annealing because of microstructural refinement.

Key words: high $\mathrm{Nb}-\mathrm{TiAl}$ alloy; heat treatment; microstructure; tensile property

CLC numbers: TG146.23; Document code: A; Article ID: 1672-6421 2020)06-447-08

$\mathrm{H}$ gh $\mathrm{Nb}$-TiAl alloys are a type of newly-developed high temperature high-strength TiAl alloys. Compared with conventional TiAl alloys, high Nb-TiAl alloys show higher specific yield strength and specific stiffness, better creep and oxidation resistance at high temperature, and their service temperature is about $100{ }^{\circ} \mathrm{C}$ higher than that of conventional TiAl alloys ${ }^{[1-4]}$. Chen et al. ${ }^{[5]}$ reported that yield strength of Ti-45Al-8Nb single crystals fabricated by directional solidification maintains a high of $637 \mathrm{MPa}$, with $8.1 \%$ ductility and superior creep resistance at $900{ }^{\circ} \mathrm{C}$. The oxidation resistance of high $\mathrm{Nb}$ TiAl alloys is similar to that of common Ni-based superalloy and the specific yield strength of high $\mathrm{Nb}$-TiAl alloys is obviously higher than that of Ni-based superalloy ${ }^{[6,7]}$. However, the applications of as-cast high $\mathrm{Nb}$-TiAl alloys are limited due to their bad plasticity at room temperature. Therefore, high $\mathrm{Nb}$-TiAl alloys are usually optimized by thermomechanical deformation such as high temperature forging, extrusion and subsequent heat treatment to improve their room temperature plasticity ${ }^{[7-10]}$.

The tensile plasticity at room temperature of as-cast Ti-43Al-7( Nb, Mo)-0.2B alloy (in at.\%) was improved from less than $0.4 \%$ to more than $1.0 \%$ in the cast + heat-treated condition (annealed at $700{ }^{\circ} \mathrm{C}$ ) and the alloy after improved ductility (formability) could be used for near-net shape forming using closed-die forging without the high-cost preliminary hot working of the ingot material, such as canned extrusion and forging. It was reported that the tensile strength was improved by heat treatment, which provided an 
enhanced fraction of the lamellar constituent and a decreased fraction of the $\beta$ phase ${ }^{[1,11]}$. Takeyama et al. ${ }^{[12]}$ found disordered $\beta$ phase can be introduced into the high temperature structure of the alloy by adding $\beta$ phase stable elements. At high temperature, $\beta$ phase can provide more slip systems, which can significantly improve the thermoforming ability of TiAl alloy. As a widely used $\beta$ phase stabilized element, $\mathrm{Nb}$ could improve the strength, creep resistance and high temperature oxidation resistance of TiAl alloys, so high Nb-TiAl alloys with good thermoforming ability have been a hot research area in recent years ${ }^{[13-17]}$. According to the phase diagrams of TiAl alloys containing $\mathrm{Nb}{ }^{[18]}$, the addition of $\mathrm{Nb}$ could decrease $\alpha$ phase transition temperature and enlarge $\beta$ phase region significantly. However, the deformation activation energy of high $\mathrm{Nb}-\mathrm{TiAl}$ alloys is much higher than that of conventional TiAl alloys due to the addition of $\mathrm{Nb}$, and the severe deformable resistance leads to hot deformation difficulty of high $\mathrm{Nb}$-TiAl alloy ${ }^{[19,20]}$. Moreover, with the increase of $\mathrm{Nb}$ content, the elements tend to segregate and the difficulty of alloy melting increases ${ }^{[21]}$.

Therefore, the high $\mathrm{Nb}$-TiAl alloys with appropriate microstructure and excellent ductility (formability) have become an important research field in recent years. In this study, an ingot of high $\mathrm{Nb}-\mathrm{TiAl}$ alloy with nominal composition of Ti-44Al$8 \mathrm{Nb}-0.2 \mathrm{~W}-0.2 \mathrm{~B}-0.5 \mathrm{Y}$ (at.\%) was fabricated by vacuum arc remelting (VAR). To eliminate porosity, hot-isostatic pressing (HIP) was performed on the alloy followed by a homogenizing annealing. Then, the effect of heat treatment on the solidification behavior, microstructure and tensile property at room temperature of the alloy was investigated. In addition, a containerless nearisothermally forged thermomechanical processing was carried out using the high Nb-TiAl alloy after HIP and annealing, and the microstructure and tensile property of as-forged were investigated.

\section{Experimental procedure}

The high Nb-TiAl alloy ingot with the nominal chemical composition of Ti-44Al-8Nb-0.2W-0.2B-0.5Y (at.\%) was fabricated by vacuum arc remelting (VAR). The raw materials used in this study were commercial purity titanium (99.9wt.\%), aluminum (99.9wt.\%), tungsten (99.9wt.\%), boron powder (99.9wt.\%), Al-Nb binary alloy (with $\mathrm{Nb}$ content of 55wt.\%) and Y-Al binary alloy (with Y content of $85 \mathrm{wt} . \%$ ). The ingot was remelted 3 times to ensure the homogeneity. The size of the ingot was about $\Phi 220 \mathrm{~mm} \times 500 \mathrm{~mm}$, as shown in Fig. 1 . In order to eliminate casting porosity, the as-cast high $\mathrm{Nb}$ TiAl alloy ingot was subjected to hot-isostatic pressing at $1,300{ }^{\circ} \mathrm{C}$ and $120 \mathrm{MPa}$ for $3 \mathrm{~h}$ under argon atmosphere with the following furnace cooling, and a homogenizing annealing process was performed at $1,250{ }^{\circ} \mathrm{C}$ for $6 \mathrm{~h}$ after HIP. Then, samples cut from the ingot were heated to $1,400{ }^{\circ} \mathrm{C}, 1,340{ }^{\circ} \mathrm{C}$ and $1,250^{\circ} \mathrm{C}$, respectively, and held for $30 \mathrm{~min}$ followed by water cooling or furnace cooling. The ingot after HIP and annealing was containerless near-isothermally forged to blanks with a total engineering strain of $75 \%$ through two-step forging

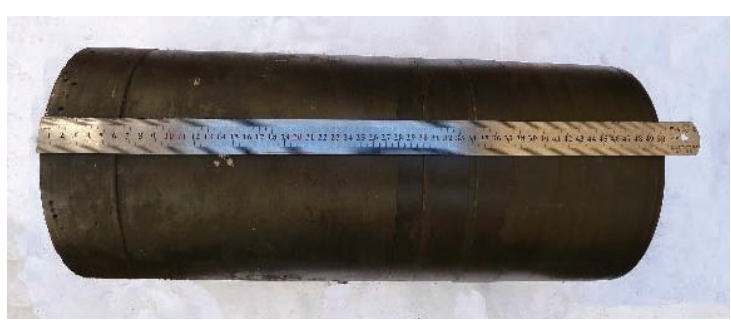

Fig. 1: Ti-44AI-8Nb-0.2W-0.2B-0.5Y alloy ingots fabricated by VAR

at $1,340{ }^{\circ} \mathrm{C}$. The forged blanks were air cooled or furnace cooled after forging. The forging blanks were held in furnace between the two forging steps.

The phase constitution of the samples was determined by X-ray diffraction (XRD) with $\mathrm{Cu} \mathrm{K}_{\alpha}$ radiation $(\lambda=1.54056 \AA)$. Microstructure was observed by scanning electron microscopy (SEM) equipped with energy dispersive spectrometer (EDS) in backscattered electron mode (BSE), and the specimens for SEM observations were mechanical polished firstly and followed by twin-jet electropolishing. The electrolytic polishing solution is $6 \%$ perchloric acid, $34 \%$ butanol and $60 \%$ methanol.

The room temperature tensile tests were conducted on the Instron 5569 universal test machine with a nominal strain rate of $4 \times 10^{-5} \mathrm{~s}^{-1}$, and the tensile samples had a gauge section of $3 \mathrm{~mm} \times 2 \mathrm{~mm} \times 18 \mathrm{~mm}$ (gauge length). Also, the fracture morphology of tensile samples was characterized by SEM.

\section{Results and discussion}

\subsection{Microstructure and solidification path of alloy}

Figure 2 shows the XRD pattern of the Ti- $44 \mathrm{Al}-8 \mathrm{Nb}-0.2 \mathrm{~W}$ $0.2 \mathrm{~B}-0.5 \mathrm{Y}$ alloy after HIP and annealing. It can be seen that the phases of $\gamma$-TiAl and $\alpha_{2}-\mathrm{Ti}_{3} \mathrm{Al}$ as well as a small amount of $\beta / \mathrm{B} 2$ are identified, and the $\beta / \mathrm{B} 2$ is introduced by the addition of $\mathrm{Nb}$ and $\mathrm{W}$ which are $\beta$ stable elements. As is known, $\beta / \mathrm{B} 2$ phase is an ordered phase with a $\mathrm{CsCl}$ structure at room temperature, but it would transform to disordered ductile phase at high temperature and have a solid lubrication effect during the hot deformation.

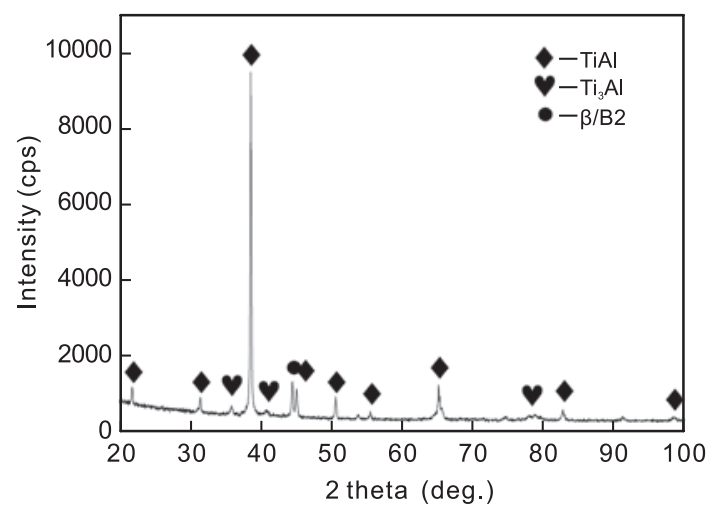

Fig. 2: XRD pattern of Ti-44AI-8Nb-0.2W-0.2B-0.5Y alloy after HIP and annealing 
The microstructure of Ti-44Al-8Nb-0.2W-0.2B-0.5Y alloy after HIP and annealing is shown in Fig. 3. The EDS analysis result of some positions in Fig. 3(b) is shown in Table 1. According to the results, the microstructure was mainly composed of $\gamma / \alpha_{2}$ colonies with a size of 20-100 $\mu \mathrm{m}$ [marked as B in Fig. 3(b)] surrounded by irregular strip or block $\beta / \mathrm{B} 2$ grains [marked as $\mathrm{C}$ in Fig. 3(b)], and a few block $\gamma$ grains [marked as $\mathrm{A}$ in Fig. 3(b)] were found distributed at the lamellar colony boundaries. These equiaxed $\gamma$ phases are precipitated from the high temperature $\beta$ phase during the cooling process. A few white small particles [marked as D in Fig. 3(b)] in the $\gamma / \alpha_{2}$ colonies are identified as $\mathrm{YAl}_{2}$ phase according to the EDS result. These $\mathrm{YAl}_{2}$ could reduce the lamellae distance, so the deformation activation energy would be decreased and the hot deformation ability of the high $\mathrm{Nb}$-TiAl alloy could be improved ${ }^{[22]}$.

According to the phase diagram of high $\mathrm{Nb}-\mathrm{TiAl}$ alloy as
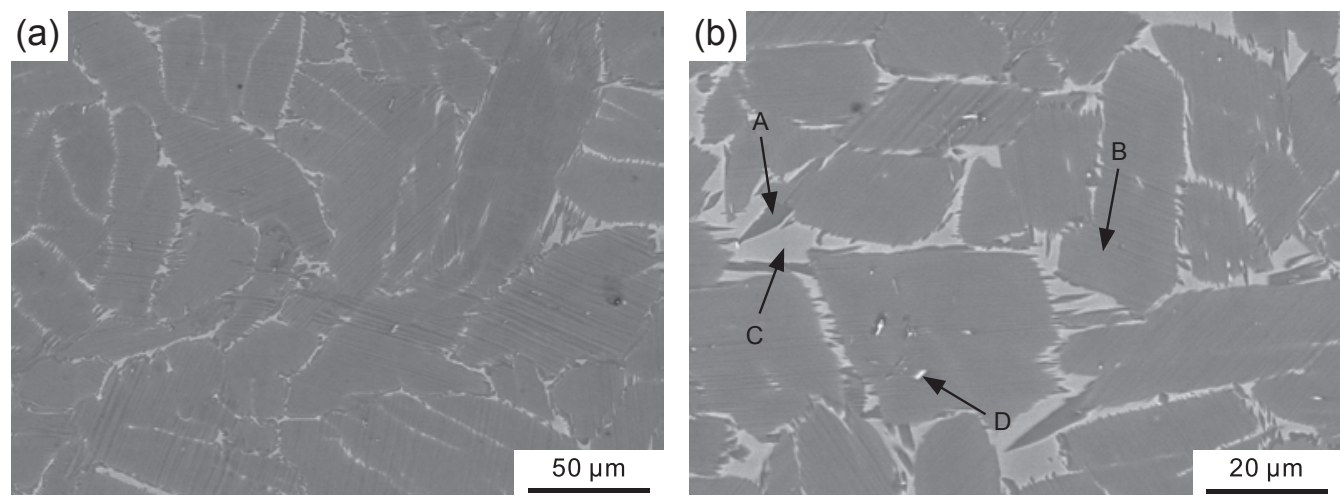

Fig. 3: SEM images of Ti-44AI-8Nb-0.2W-0.2B-0.5Y alloy: (a) low magnification; (b) high magnification

Table 1: EDS results of the high Nb-TiAl alloy at different positions in Fig. 3(b) (at.\%)

$\begin{array}{cccccccc}\text { Position } & \text { Ti } & \text { Al } & \text { Nb } & \text { W } & \text { B } & \text { Y } \\ \text { A } & 44.85 & 46.96 & 7.87 & 0.17 & 0.15 & 0 \\ \text { B } & 55.7 & 35.43 & 8.48 & 0.21 & 0.18 & 0 \\ \text { C } & 49.68 & 39.62 & 10.35 & 0.16 & 0.19 & 0 \\ \text { D } & 25.81 & 46.43 & 5.34 & 0 & 0 & 22.42\end{array}$

shown in Fig. $4^{[17]}$ and microstructure characteristic of the Ti-44Al-8Nb-0.2W-0.2B-0.5Y alloy as shown in Fig. 3, the solidification path of this high $\mathrm{Nb}$-TiAl alloy can be analyzed. The $\beta$ phase firstly nucleates and grows in the melt when the temperature begins to decrease. Due to the addition of $\mathrm{Nb}$, the $\beta$ phase region is extended and the phase transition temperature of $\beta$ phase to $\alpha$ phase decreases, the peritectic reaction $(\beta+\mathrm{L} \rightarrow \alpha)$ does not occur during solidification, so the liquid phase transforms to $\beta$ phase completely. The $\beta$ phase is not stable at high temperature; $\alpha$ phase would precipitate from $\beta$ phase obeying the Burgers relationship ${ }^{[23]}$. With the further decrease of temperature, $\gamma / \alpha_{2}$ colonies are formed finally. Therefore, the

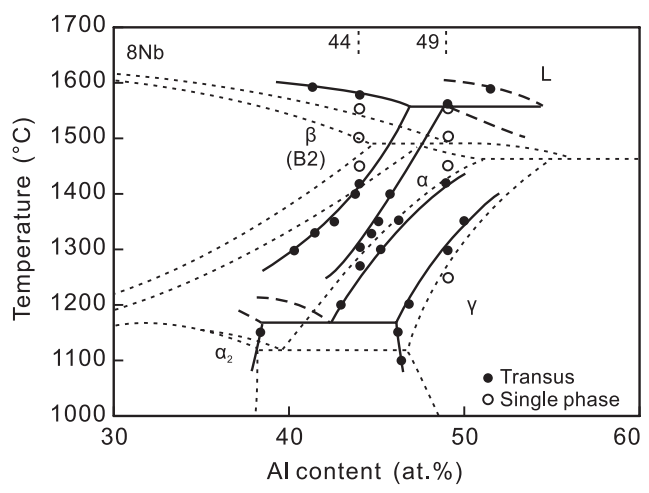

solidification path of this high $\mathrm{Nb}-\mathrm{TiAl}$ alloy is speculated as follows: $L \rightarrow L+\beta \rightarrow \beta \rightarrow \alpha+\beta \rightarrow \alpha \rightarrow \alpha+\beta+\gamma \rightarrow \alpha_{2}+\beta+\gamma$. Dendrite segregation caused by peritectic reaction is avoided, so the composition uniformity of alloy is improved ${ }^{[24]}$. Furthermore, as all $\alpha$ phases are transformed by solid phase transformation, the orientation of $\alpha$ phase will not be affected by the temperature gradient of liquid state, and the orientation will become diversified, eventually forming lamellae with various orientations. Moreover, there are three equivalent orientations $(<100>\beta$ axis) for preferential crystal growth including [100], [010] and [001] during solidification, and the microstructure might be refined ${ }^{[25]}$.

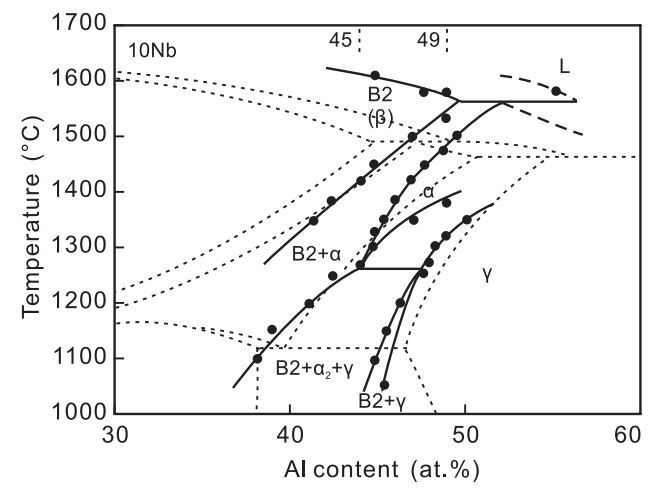

Fig. 4: Effect of $\mathrm{Nb}$ content on TiAl alloy phase diagram ${ }^{[18]}$ 


\subsection{Effect of heat treatment on microstructure}

To research the phase constitution of the high Nb-TiAl alloy at high temperatures, the alloy samples after HIP and annealing were heated at temperatures of $1,400{ }^{\circ} \mathrm{C}, 1,340{ }^{\circ} \mathrm{C}$ and $1,250{ }^{\circ} \mathrm{C}$ for $30 \mathrm{~min}$, respectively, followed by water quenching or furnace cooling. Figure 5 shows the microstructure of the alloy after water quenching at different temperatures. As shown in Fig. 5(a), the microstructure of Ti-44Al-8Nb-0.2W-0.2B$0.5 \mathrm{Y}$ alloy quenched at $1,400{ }^{\circ} \mathrm{C}$ is mainly composed of gray block $\alpha$ phase and a few thin strip white $\beta / \mathrm{B} 2$ phase located in the $\alpha$ phase grain boundary. When the alloy is quenched at
$1,340{ }^{\circ} \mathrm{C}$, the white $\beta / \mathrm{B} 2$ phases disappear completely and the microstructure is composed of $\alpha$ phase. The grain size of the $\alpha$ phase is smaller than that of the alloy quenched at $1,400{ }^{\circ} \mathrm{C}$. When the quenching temperature is reduced to $1,250{ }^{\circ} \mathrm{C}$, a lot of black acicular $\gamma$ phases appear and $\gamma / \alpha_{2}$ colonies form in the microstructure. Also, it is found that $\beta / \mathrm{B} 2$ phase is uniformly distributed at the lamellar boundary. It can be concluded that this high $\mathrm{Nb}$-TiAl alloy is in $\alpha+\beta$ two-phase region at $1,400{ }^{\circ} \mathrm{C}, \alpha$ single phase region at $1,340{ }^{\circ} \mathrm{C}$ and $\alpha+\beta+\gamma$ three-phase region at $1,250{ }^{\circ} \mathrm{C}$.
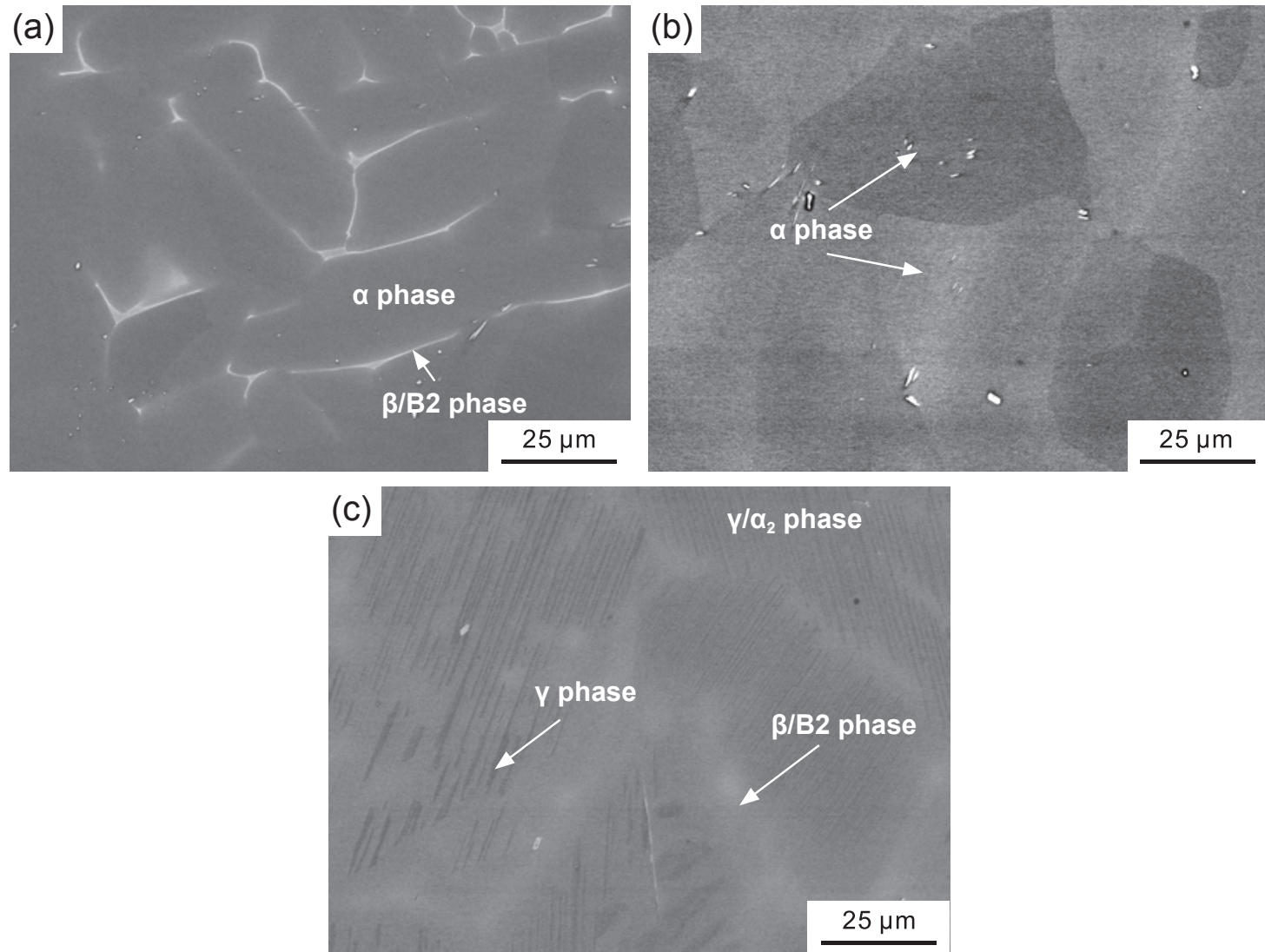

Fig. 5: Microstructures of Ti-44Al-8Nb-0.2W-0.2B-0.5Y alloy heated at different temperatures followed by water quenching: (a) $1,400^{\circ} \mathrm{C}$; (b) $1,340^{\circ} \mathrm{C}$; (c) $1,250^{\circ} \mathrm{C}$

Figure 6 shows the microstructure of the Ti-44Al- $8 \mathrm{Nb}-0.2 \mathrm{~W}$ $0.2 \mathrm{~B}-0.5 \mathrm{Y}$ alloy heat treated at different temperatures followed by furnace cooling. When the alloy is heated at $1,400{ }^{\circ} \mathrm{C}(\alpha+\beta$ phases region), a full lamellar (FL) structure of $\gamma / \alpha_{2}$ lamellar is obtained after furnace cooling (Fig. 6a). Due to this, high $\mathrm{Nb}$-TiAl alloy is solidified through the $\beta$ phase, the $\beta$ phase transforms to $\alpha$ phase at an early cooling stage, and it has been revealed that this transformation could happen by following the orientation relationship of $\{1 \overline{1} 0\}_{\beta} / /(0001)_{\alpha}$ and $<111>_{\beta}$ $/ /<11 \overline{2} 1>_{\alpha}{ }^{[25]}$. With the further cooling, the lath $\gamma$ phase precipitates from $\alpha$ phase following the Blackburn orientation relationship. Finally, $\alpha$ grain transforms to $\gamma / \alpha_{2}$ colonies, and $\beta / \mathrm{B} 2$ phase disappears completely. The microstructure of the alloy heat treated at $1,340{ }^{\circ} \mathrm{C}$ ( $\alpha$ single phase region) is similar to that heat treated at $1,400{ }^{\circ} \mathrm{C}$, but the size of lamellar colonies is refined. A near lamellar (NF) microstructure is obtained after the alloy is heat treated at $1,250{ }^{\circ} \mathrm{C}(\alpha+\beta+\gamma$ phases region $)$, and there are still a few strip $\beta / \mathrm{B} 2$ grains and block $\gamma$ phase in the boundary of fine lamellar colonies. Due to the precipitation of $\alpha$ phase during the furnace cooling process, the segregation of $\beta$ stabilizer $\mathrm{Nb}$ would occur and $\beta / \mathrm{B} 2$ phase formed in the lamellar boundary, so there are still a large amounts of $\beta / B 2$ phase in the microstructure at room temperature. It is worth noting that the lamellar colonies are refined and the size is about $60-100 \mu \mathrm{m}$ when this high Nb-TiAl alloy is heat treated at $1,250{ }^{\circ} \mathrm{C}$. The refinement of lamellar colonies is caused by the lower heat treatment temperature which limits the rapid growth of grains during the holding process. Also, the $\beta$ phase and $\gamma$ phase in the alloy can be considered as second phases to suppress the growth of $\gamma / \alpha_{2}$ lamellar colonies. 

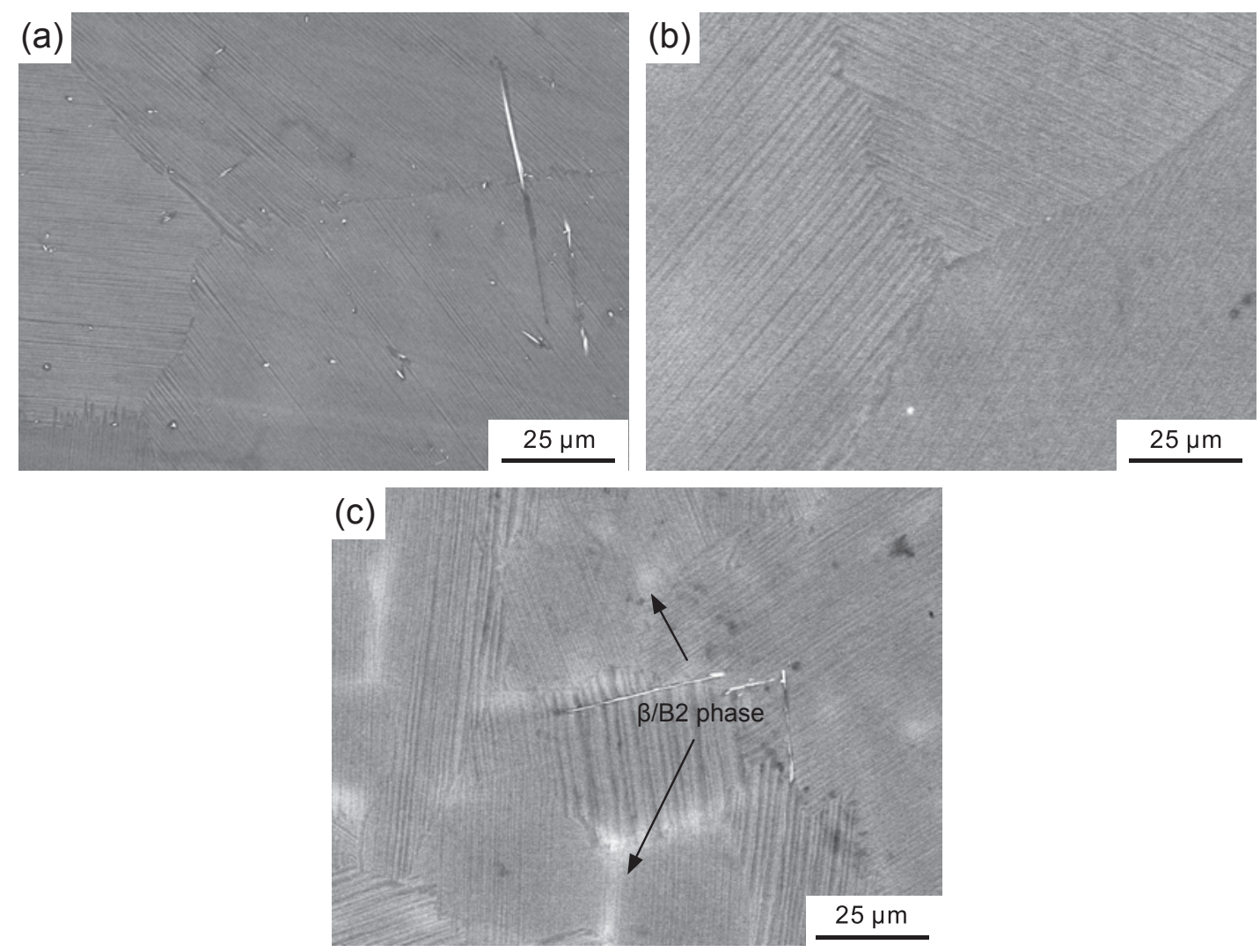

Fig. 6: Microstructures of Ti-44Al-8Nb-0.2W-0.2B-0.5Y alloy heat treated at different temperatures by furnace cooling: (a) $1,400^{\circ} \mathrm{C}$; (b) $1,340^{\circ} \mathrm{C}$; (c) $1,250^{\circ} \mathrm{C}$

\subsection{Tensile property of Ti-44AI-8Nb-0.2W-0.2B- $0.5 \mathrm{Y}$ alloy}

Figure 7 shows the strain-stress curves of the Ti-44Al-8Nb$0.2 \mathrm{~W}-0.2 \mathrm{~B}-0.5 \mathrm{Y}$ alloy in different conditions tested at room temperature with a strain rate of $4 \times 10^{-5} \mathrm{~s}^{-1}$. According to the strain-stress curves, it can be found that the high $\mathrm{Nb}$-TiAl alloy without heat treatment exhibited brittle fracture, and the ultimate tensile strength was $538 \mathrm{MPa}$, with an elongation of $0.3 \%$. After the alloy was heated at $1,340{ }^{\circ} \mathrm{C}$ followed by furnace cooling, the ultimate tensile strength of the alloy was $561 \mathrm{MPa}$, with an elongation of $0.44 \%$. The alloy after HIP and annealing is mainly composed of $\gamma / \alpha_{2}$ colonies and a small amount of the $\beta / B 2$ phase. Stress concentration easily occurs in anisotropic lamellar colonies during the tensile process, and the stress concentration results in the fracture of alloy. Ordered brittle $\beta / \mathrm{B} 2$ phases at the lamellar boundary also lead to the brittle fracture failure of the Ti-44Al-8Nb-0.2W-0.2B-0.5Y alloy. The tensile property of the Ti-44Al-8Nb-0.2W-0.2B-0.5Y alloy heated at $1,340{ }^{\circ} \mathrm{C}$ is improved because the size of lamellar colonies is refined.

The fracture surfaces of the Ti-44Al-8Nb-0.2W-0.2B-0.5Y alloy were analyzed to further clarify the fracture mechanism, as shown in Fig. 8. A typical brittle cleavage fracture [Figs. 8(a) and (b)] was identified in the fracture surface because of its coarse lamellar colony of the alloy. The fracture surface shows river pattern characteristics, and there is no obvious tearing resistance. The coordinate deformation of lamellae is poor due to the different orientations of lamellae and the

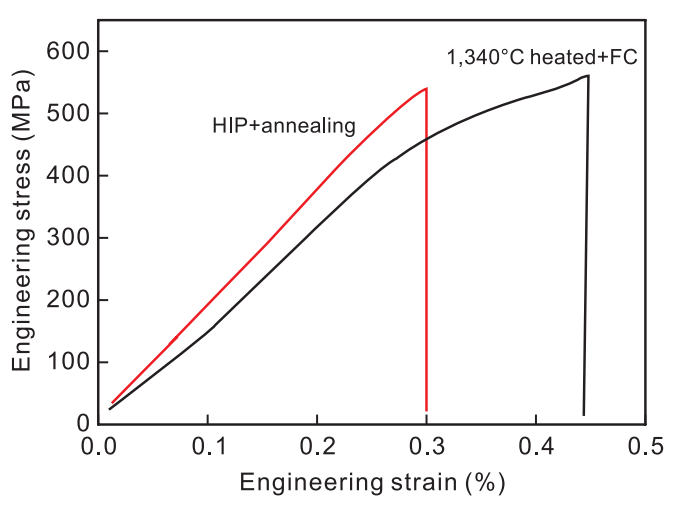

Fig. 7: Strain-stress curves of Ti-44AI-8Nb-0.2W-0.2B-0.5Y alloy at room temperature

stress concentration could appear easily, so cleavage fracture does not occur along a certain crystal plane, but in a group of parallel crystal planes at the same time.

In order to further study the fracture behavior, the microstructure on the side surface of the tensile specimen near the fracture zone is analyzed as shown in Figs. 8(c) and (d). The crack firstly propagates along the lamellae under the external loading condition. With the increase of external loading, the propagation path of the crack bends and the propagation mode changes from along the lamellae to through the lamellae, and there is an obvious crack bridging and a secondary crack, which works against the reduction of passivation of crack tip and produces toughening. Finally, the crack tip is passivated and the propagation stops [Region I shown in Fig. 8(d)]. 
According to the mode of crack propagation, the mechanism of crack initiation and propagation of the high $\mathrm{Nb}$-TiAl alloy can be concluded as follows: when the crack front met with a smaller angle of lamellae boundary, the deflection at the lamellae boundary and the propagation along the lamellae boundary and the crack propagation direction changed, which can effectively prevent the expansion of the crack. Secondary crack propagates along or through lamellae, and the lamellae are fractured with the increase of external loading.
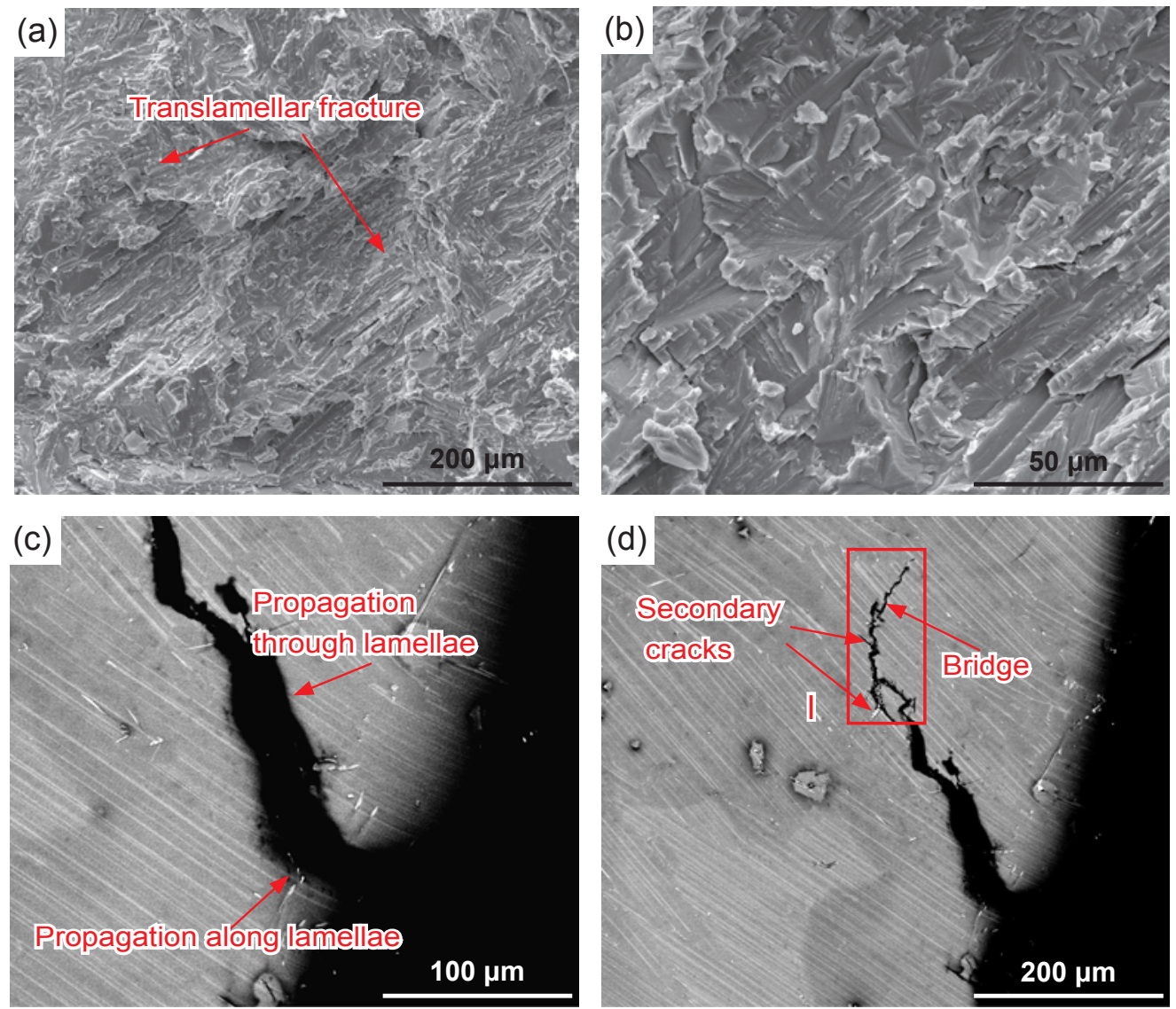

Fig. 8: Tensile fracture surface of alloy at room temperature: (a) and (b) fracture surface; (c) and (d) microstructure of the tensile specimen near the fracture zone

\subsection{Containerless near-isothermal forging}

The thermoplastic and mechanical properties of TiAl alloy could be improved by extrusion or forging in $\alpha$ single phase zone ${ }^{[26]}$. According to Tetsui's report, ordered $\beta / \mathrm{B} 2$ phase would be eliminated and a full lamellar structure would be obtained when TiAl alloy is forged in $\alpha$ phase region ${ }^{[27]}$. So the Ti-44Al-8Nb-0.2W-0.2B-0.5Y alloy was forged without acontainer at $1,340{ }^{\circ} \mathrm{C}$ by a two-step forging, and the total deformation is $75 \%$. Figure 9 shows the macro-morphology and microstructure of forged high $\mathrm{Nb}-\mathrm{TiAl}$ alloy blanks. Forged blanks with high surface quality are obtained as shown in Fig. 9(a), and there is no crack in the edge area.

Samples were cut from the center of the forged blank and the microstructure of the blank cooled in air or in furnace was observed. The microstructure of the air cooled sample mainly consists of long strip $\gamma / \alpha_{2}$ lamellar colonies, and the average size of lamellar colonies is about $35 \mu \mathrm{m}$, which is much smaller than that of the alloy before forging [shown in Figs. 9(b) and (c)]. The microstructure of the furnace cooled sample is similar to that of the air cooled sample, but the size of lamellar colonies and lamellar spacing increases. The reason is that the cooling process of a forged blank in furnace could be regarded as an annealing treatment and the lamellar colonies would grow up during the furnace cooling process. There are a few $\beta / \mathrm{B} 2$ phase and equiaxed $\gamma$ phase grains at the lamellar boundary in both air cooled and furnace cooled samples, indicating that recrystallization occurs during the forging and cooling processes. The $\alpha$ phase grains can significantly deform when the alloy is forged in $\alpha$ single phase region and subsequently transformed into $\gamma / \alpha_{2}$ lamellae during cooling.

Figure 10 shows the room temperature tensile properties of the Ti-44Al-8Nb-0.2W-0.2B-0.5Y alloy blank forged at $1,340{ }^{\circ} \mathrm{C}$ ( $\alpha$ single phase region). The tensile properties of the as-forged alloy were obviously improved. As shown in Fig. 10, the elongation of both the air cooled sample and the furnace cooled sample is about $0.9 \%$, but the ultimate tensile strength of the air cooled sample is about $820 \mathrm{MPa}$, and that of the furnace cooled sample is about $750 \mathrm{MPa}$. The cooling mode has little effect on tensile elongation, but affects the tensile strength significantly. With the increase of cooling rate, residual stress and dislocation density of air cooled specimen 

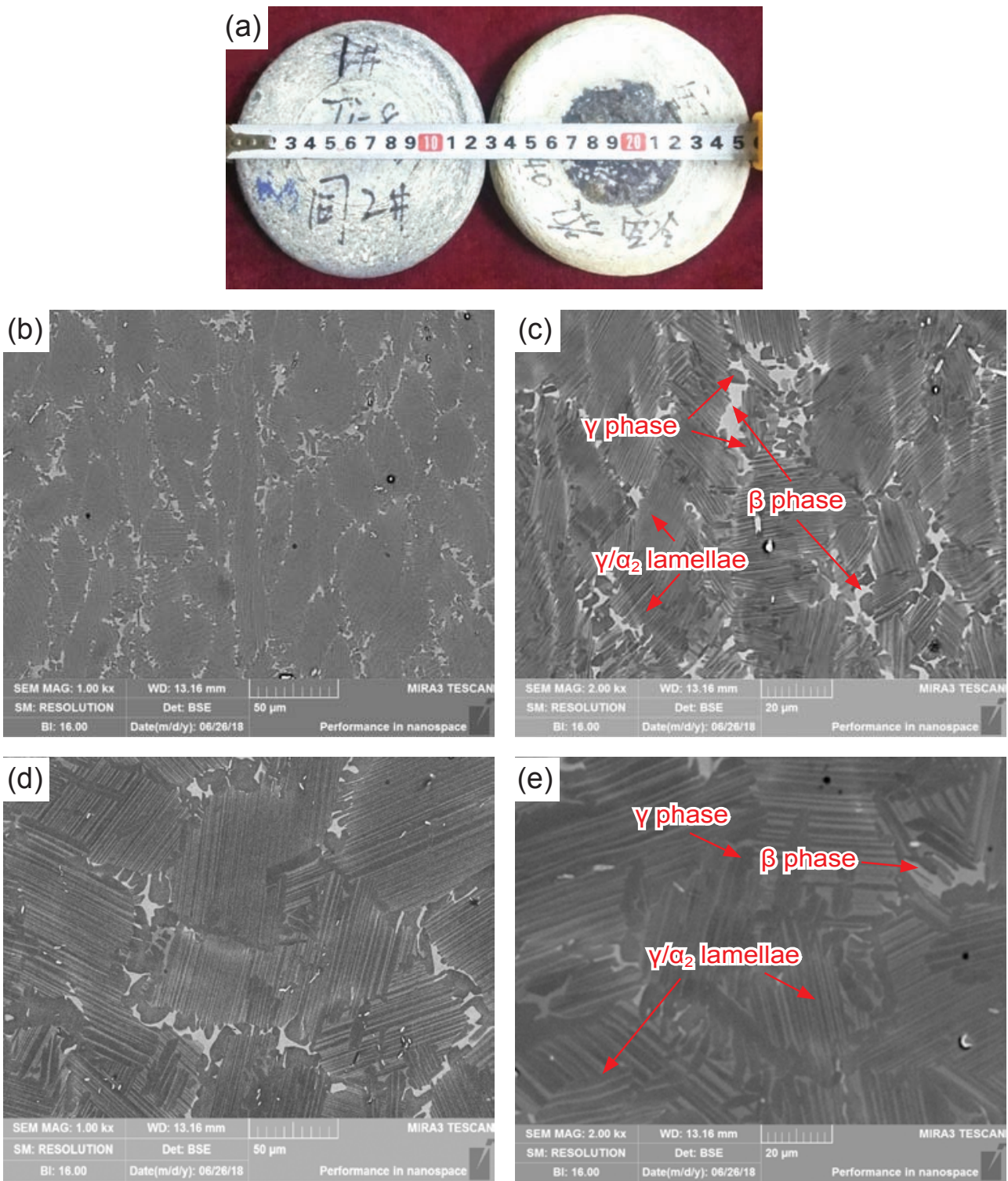

Fig. 9: Macrograph and microstructure of Ti-44Al-8Nb-0.2W-0.2B-0.5Y alloy forged at $1,340^{\circ} \mathrm{C}$ :

(a) macrograph of as-forged blanks; (b) and (c) microstructure of air cooled as-forged blanks;

(d) and (e) microstructure of furnace cooled as-forged blanks

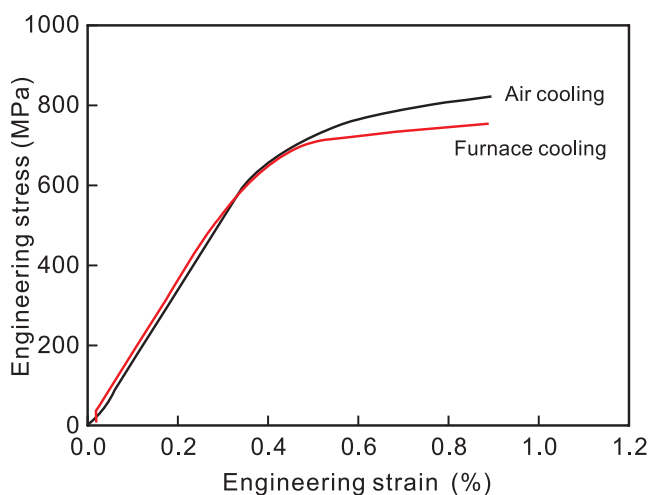

Fig. 10: Stress-strain curves of Ti-44Al-8Nb-0.2W-0.2B-0.5Y alloy at room temperature after forging at $1,340^{\circ} \mathrm{C}$ ( $\alpha$ single phase region)

are higher than that of furnace cooled specimen. The room temperature deformation of TiAl alloy is mainly dependent on the $\gamma$ phase, and multiple dislocation slip is the main mechanism during room temperature tensile deformation. The improvement of tensile strength of the forged alloy could be ascribed to the refinement of lamellar colony microstructure. Because the lamellar colony size and lamellar spacing of the air cooled sample are smaller than the furnace cooled sample, the dislocation slip would be effectively hindered by grain boundaries, which is more beneficial to improve the tensile strength of alloy at room temperature.

\section{Conclusions}

In this study, the microstructure evolution and tensile property of the high Nb-TiAl alloy (Ti-44Al-8Nb-0.2W-0.2B-0.5Y, after HIP and annealing) after heat treatment and thermomechanical processing were studied, respectively. The main conclusions are summarized as follows:

(1) The microstructure of the Ti-44Al-8Nb-0.2W-0.2B-Y alloy after HIP and annealing mainly consists of coarse $\alpha_{2} / \gamma$ lamellae, 
$\beta /$ B2 phase at the lamellar colony boundaries and a small amount of equiaxed $\gamma$ phases. The solidification path of this high $\mathrm{Nb}$-TiAl alloy is: $\mathrm{L} \rightarrow \mathrm{L}+\beta \rightarrow \beta \rightarrow \alpha+\beta \rightarrow \alpha \rightarrow \alpha+\beta+\gamma \rightarrow \alpha_{2}+\beta+\gamma$. The alloy exhibits typical brittle cleavage fracture, and the ultimate tensile strength is about $538 \mathrm{MPa}$, with an elongation of $0.3 \%$ at room temperature.

(2) When the Ti-44Al-8Nb-0.2W-0.2B-Y alloy is water quenched at $1,340{ }^{\circ} \mathrm{C}$, the white $\beta / \mathrm{B} 2$ phase disappears completely and the microstructure is composed of $\alpha$ phase. A fully lamellae structure of $\gamma / \alpha_{2}$ lamellar is obtained after the alloy is heat treated at $1,340{ }^{\circ} \mathrm{C}$ followed by furnace cooling.

(3) Crack-free blanks are fabricated via containerless nearisothermal forging at $1,340{ }^{\circ} \mathrm{C}$ ( $\alpha$ single phase region). Compared with tensile property of the high $\mathrm{Nb}$-TiAl alloy before forging, the ultimate tensile strength of forged high $\mathrm{Nb}$-TiAl alloy in furnace cooled condition is increased from $538 \mathrm{MPa}$ to $820 \mathrm{MPa}$, and the elongation at room temperature increases from $0.3 \%$ to $0.9 \%$.

\section{Acknowledgments}

This research was sponsored by the National Natural Science Foundation of China (Project Nos.: 51971074, 51471056), the State Key Laboratory for Advanced Metal and Materials Foundation (Project No.: 2013-ZD06), and the National Basic Research Program of China (Project No.: 2011CB605502).

\section{References}

[1] Gong S K, Shang Y, Zhang J, et al. Application and research of typical intermetallics-based high temperature structural materials in China. Acta Metallurgica Sinica, 2019, 55(9): 1067-1096. (In Chinese)

[2] Lin J P, Zhao L L, Li G Y, et al. Effect of $\mathrm{Nb}$ on oxidation behavior of high $\mathrm{Nb}$ containing TiAl alloys. Intermetallics, 2011, 19(2): 131-136.

[3] Hu D, Mei J F, Wickins M, et al. Microstructure and tensile properties of investment cast Ti-46Al-8Nb-1B alloy. Scripta Materialia, 2002, 47(4): 273-278.

[4] Appel F, Brossmann U, Christoph U, et al. Recent progress in the development of gamma titanium aluminide alloys. Advanced Engineering Materials, 2000, 2(11): 699-720.

[5] Chen G, Peng Y B, Zheng G, et al. Polysynthetic twinned TiAl single crystals for high-temperature applications. Nature Materials, 2016, 15: 876-881.

[6] Yoshihara M, Kim Y W. Oxidation behavior of gamma alloys designed for high temperature applications. Intermetallics, 2005, 13(9): 952-958.

[7] Kothari K, Radhakrishnan R, Wereley N M. Advances in gamma titanium aluminides and their manufacturing techniques. Progress in Aerospace Sciences, 2012, 55: 1-6.

[8] Gao S B, Liang Y F, Ye T, et al. In-situ control of microstructure and mechanical properties during hot rolling of high-Nb TiAl alloy. Materialia, 2018, 1: 229-235.

[9] Zhou H T, Kong F T, Wang X P, et al. Hot deformation behavior and microstructural evolution of as-forged Ti-44Al-8Nb-(W, B, Y) alloy with nearly lamellar microstructure. Intermetallics, 2017, 81: $62-72$.
[10] Singh V, Mondal C, Sarkar R, et al. Dynamic recrystallization of a $\beta$ (B2)-stabilized $\gamma$-TiAl based Ti-45AI-8Nb-2Cr-0.2B alloy: The contributions of constituent phases and Zener-Hollomon parameter modulated recrystallization mechanisms. Journal of Alloys and Compounds, 2020, 828: 154386.

[11] Imayev V, Imayev R, Khismatullin T. Superplastic behavior of Ti-43Al-7(Nb,Mo)-0.2B alloy in the cast + heat-treated condition. Scripta Materialia, 2007, 57(3): 193-196.

[12] Takeyama M, Kobayashi S. Physical metallurgy for wrought gamma titanium aluminides microstructure control through phase transformations. Intermetallics, 2005, 13(9): 993-999.

[13] Cha L, Clemens H, Dehm G. Microstructure evolution and mechanical properties of an intermetallic Ti-43.5Al-4Nb-1Mo0.1B alloy after ageing below the eutectoid temperature. International Journal of Materials Research, 2011, 102(6): 703-708.

[14] Wang Y Z, Ding H S, Chen R R, et al. A high-Nb TiAl alloy with highly refined microstructure and excellent mechanical properties fabricated by electromagnetic continuous casting. China Foundry, 2016, 13(5): 342-345.

[15] Appel F, Paul J D H, Oehring M. Gamma titanium aluminide alloys. Wiley-VCH Verlag $\mathrm{GmbH} \& \mathrm{Co}, \mathrm{KGaA}$, Weinheim, 2011: 465-478.

[16] Xu X J, Lin J P, Wang $Y L$, et al. Effect of forging on microstructure and tensile properties of Ti-45Al-(8-9)Nb-(W, B, Y) alloy. Journal of Alloys and Compounds, 2006, 414(1-2): 175-180.

[17] Tang B, Cheng L, Kou H C, et al. Hot forging design and microstructure evolution of a high $\mathrm{Nb}$ containing TiAl alloy. Intermetallics, 2015, 58: 7-14.

[18] Liang Y F, Xu X J, Lin J P. Advances in phase relationship for high Nb-containing TiAl alloys. Rare Metals, 2016, 35(1): 15-25.

[19] Song X P, Chen G L. Determination of the stacking fault energy in high-Nb $\mathrm{y}$-TiAl. Journal of Materials Science Letters, 2001, 20(7): 659-661.

[20] Paul J D H, Appel F, Wagner R. The compression behaviour of niobium alloyed $y$-titanium aluminides. Acta Mater. 1998, 46(4): 1075-1085.

[21] Wang $Y H$, Lin J P, He $Y H$, et al. Microstructure and mechanical properties of as-cast Ti-45Al-8.5Nb-(W,B,Y) alloy with industrial scale. Materials Science and Engineering $A$, 2007, 471(1-2): 82-87.

[22] Chen Y Y, Li B H, Kong F T. Microstructural refinement and mechanical properties of $Y$-bearing TiAl alloys. Journal of Alloys and Compounds, 2008, 457(1-2): 265-269.

[23] Imayev R M, Imayev V M, Oehring M, et al. Alloy design concepts for refined gamma titanium aluminide based alloys. Intermetallics, 2007, 15(4): 451-460.

[24] Xu Z F, Xu X J, Lin J P, et al. Effect of heat treatment on $\mathrm{S}$-segregation of microstructure for as-cast high $\mathrm{Nb}$ containing TiAl Alloy. Journal of Aeronautical Materials, 2007, 27(3): 113117. (In Chinese)

[25] Jin Y G, Wang J N, Yang J, et al. Microstructure refinement of cast TiAl alloys by $\beta$ solidification. Scripta Mater, 2004, 51(2): $113-117$.

[26] Kim Y W. Advances in the fundamental understanding for designing engineering gamma TiAl alloys. Transactions of the Chinese Institute of Chemical Engineers, 1999, 22(1): 13-25.

[27] Tetsui T, Shindo K, Kaji S, et al. Fabrication of TiAl components by means of hot forging and machining. Intermetallics, 2005, 13(9): 971-978. 